\title{
Variability of extreme events in East Asia and their dynamical control: A comparison between observations and two
}

\section{${ }_{3}$ high-resolution global climate models.}

\author{
4 N. Freychet $\cdot$ A. Duchez $\cdot$ C.-H. Wu $\cdot$ C.-A.
}

5 Chen · H.-H. Hsu · J. Hirschi · A. Forryan · B.

6 Sinha · A. L. New · T. Graham - M. B. Andrews

7 C.-Y. Tu · S.-J. Lin

8 Received: date / Accepted: date

9 Abstract This work investigates the variability of extreme weather events (drought spells,

10 DS15, and daily heavy rainfall, PR99) over East Asia. It particularly focuses on the large

11 scale atmospheric circulation associated with high levels of the occurrence of these extreme

Nicolas Freychet $\cdot$ C.-H. Wu · C.-A. Chen · H.-H. Hsu · C.-Y. Tu

Research Center for Environmental Changes, Academia Sinica, Taipei 105, Taiwan

Tel.: +886-2-2787-1932

Fax: +886-2-2787-1924

E-mail: nfreychet@gate.sinica.edu.tw

A. Duchez $\cdot$ J. Hirschi $\cdot$ A. Forryan · B. Sinha $\cdot$ A. L. New

National Oceanography Centre European Way, Southampton, SO14 3ZH, UK

M. B. Andrews · T. Graham

Hadley Centre, Met Office, Exeter, EX1 3PB, UK

S.-J. Lin

NOAA/Geophysical Fluid Dynamics Laboratory, Princeton University, Princeton, NJ, USA 
12 events. Two observational datasets (APHRODITE and PERSIANN) are compared with two

13 high-resolution global climate models (HiRAM and HadGEM3-GC2) and an ensemble of

14 other lower resolution climate models from CMIP5.

15 We first evaluate the performance of the high resolution models. They both exhibit good

16 skill in reproducing extreme events, especially when compared with CMIP5 results. Signif-

17 icant differences exist between the two observational datasets, highlighting the difficulty of

18 having a clear estimate of extreme events.

The link between the variability of the extremes and the large scale circulation is inves-

20 tigated, on monthly and interannual timescales, using composite and correlation analyses.

21 Both extreme indices DS15 and PR99 are significantly linked to the low level wind intensity

22 over East Asia, i.e. the monsoon circulation. It is also found that DS15 events are strongly

${ }_{23}$ linked to the surface temperature over the Siberian region and to the land-sea pressure con-

24 trast, while PR99 events are linked to the sea surface temperature anomalies over the West

25 North Pacific. These results illustrate the importance of the monsoon circulation on extremes

${ }_{26}$ over East Asia. The dependencies on of the surface temperature over the continent and the

27 sea surface temperature raise the question as to what extent they could affect the occurrence

28 of extremes over tropical regions in future projections.

${ }_{29}$ Keywords Extreme precipitation $\cdot$ Extremes variability $\cdot$ East Asia $\cdot$ High Resolution

30 Models $\cdot$ Asian Monsoon

\section{Introduction}

32 East Asia has a dense population, with more than one billion people living in China, and is

зз subject to strong seasonal atmospheric variations. The winter monsoon can bring dry and

34 cold air from Northern-Asia, while the summer monsoon is characterized by warm and wet 
air advected from the tropical Indopacific region. This dynamics has been reviewed in many

36 papers and books (e.g. Ramage, 1971; Ding, 1994; Jhun and Lee, 2003; Wang, 2006; Ding,

37 2007; Wang et al., 2008; Wang and Chen, 2014; Matsumura et al., 2015; Liu et al., 2015).

Depending on the season, East Asia can also be impacted by droughts and floods which

39 can have considerable socio-economic impacts. A number of studies have focused on the

40 variations of major extreme events in recent warming decades and/or a potential future cli-

${ }_{41}$ mate change (Trenberth et al., 2003; Kharin and Zwiers, 2005; Meehl et al., 2005; Risnen,

42 2005; Barnett et al., 2006; Tebaldi et al., 2006; Giorgi et al., 2011; Shiu et al., 2012; Scoc-

43 cimarro et al., 2013). The Intergovernmental Panel on Climate Change Fourth Assessment

44 Report (IPCC AR4) provides a summary of the associated studies, including projected fu-

45 ture details of the Asian region in Chapters 10.3.6 (Meehl et al., 2007) and 11.4 (Christensen

46 et al., 2007). The confidence in the spatial and temporal variations of a projected precipi-

47 tation change is sensitive, the results being usually dependent on the models, especially for

48 extreme events (Freychet et al., 2015), and it is important to understand the dynamical con-

49 nection between the changes in the monsoon circulation and extreme events (e.g. Wang and

Ding, 2006; Inoue and Ueda, 2011; Min et al., 2012; Turner and Annamalai, 2012; Duan

51 et al., 2013; Hsu et al., 2013; Jones and Carvalho, 2013; Seth et al., 2013; Kamae et al.,

52 2014).

53 If extreme events are rare by definition, their variability is also high (especially the short

54 term variability on timescales of daily to intraseasonal), and they may sometimes occur con-

55 secutively during a long period or over a large region. One important question is how the

${ }_{56}$ occurrence of extreme events over East Asia is linked to the large scale dynamics (including

${ }_{57}$ the monsoon system). In other words, is the variability of extremes mostly due to local con-

${ }_{58}$ ditions or the large scale atmospheric circulation? Previous work has shown the important

59 role of the atmospheric moisture content when studying projections (e.g. Chou and Neelin, 
60 2004; Stephens and Ellis, 2008; Chou et al., 2009; Seager et al., 2010; Giorgi et al., 2011;

61 Chen et al., 2012; Chou et al., 2012; Kusunoki and Arakawa, 2012). However, it is still un-

62 clear to what extent the dynamics and monsoon circulation could impact extreme events,

63 especially their variability. Understanding what controls this variability may help to better

64 estimate future risks.

65 One problem when studying extremes related to precipitation is their poor representation ${ }_{66}$ in the current Global Climate Models (GCMs), because of low resolution and inefficient 67 physical parametrization. Indeed, GCMs usually have low resolution (from $1.5^{\circ}$ to $3^{\circ}$ or 68 coarser in the CMIP5 models). High resolution model data are still rare and precious for 69 climate studies, especially when studying extreme events. One common approach to solve 70 this point consists of using regional climate models with higher resolution and forced by 71 low resolution GCM output at the domain boundaries. However, the use of such models is 72 limited to regional studies, and cannot be used to investigate large spatial scale correlations 73 (eg the links between the monsoonal circulation and extremes).

In this study, we use two global high-resolution state-of-the-art GCMs (introduced in 75 section 2) to investigate extremes at regional scale (over East Asia) and also to study the 76 correlations between this specific region and the global atmospheric environment. We first 77 compare these two models with observations and study how they can reproduce extreme 78 events compared to low resolution GCMs from CMIP5 (section 3). Then, the large scale 79 atmospheric controls on the seasonal and interannual variability of extreme events in the 80 observations and models is investigated in section 4 . Section 5 presents a summary and 81 discussion. 
2 Data and methodology

We first specify the region of our study and define the type of extremes we are studying

84 (section 2.1). We then present in section 2.2 the observational and model datasets used in 85 this investigation.

${ }_{86} \quad 2.1$ The East Asia region and extreme indices

\section{2.1.1 Definition of regions}

88 The precipitation climatology over East Asia and China has clearly defined patterns, as illus-

89 trated by Fig. 1. In this figure, the mean precipitation from the Tropical Rainfall Measuring

90 Mission (TRMM, Huffman et al. (2007)) is averaged between 1998 and 2013. There is a

${ }_{91}$ clear contrast between the Northwestern continental dry region, and the Southeastern wet

92 regions. The Meiyu front rain band, corresponding to the East Asian summer monsoon, can

93 be easily identified, ranging from South-East China to North-East Japan. Precipitation as-

94 sociated with the Indian summer monsoon gives rise to a further a maximum in the Bay of

95 Bengal and North-East India.

96 Because we are interested in the vulnerability of population, we focus on land areas. The ${ }_{97}$ area of interest can be divided into two sub-regions, as shown on Fig. 1 with black boxes:

${ }_{98}$ North China and Korea (NCK) and South China (SC). In the text, we also consider West

99 China (WC) which covers the West and central part of China, including Himalayan plateau. Table 1 defines the boundaries of the three regions cited above. WC is characterized by

101 very dry conditions while SC, in contrast, experiences very wet conditions. NCK has a dry tendency, but can also experience wet weather conditions during summer. This is of course

${ }_{103}$ a rough partitioning of China and East Asia region and it could be subdivided into smaller 
regions. As most of the population is concentrated in the Eastern and Southern parts, and the East Asian monsoon has stronger influence over these regions, the main part of our study will focus on these two regions (NCK and SC). However, when evaluating the models in section 3, we consider the three regions (including WC). While it would also be interesting to investigate extremes over Japan, we have chosen to focus our study on the continental part of East Asia (i.e. China and Korea).

\subsubsection{Definition of extreme indices}

There are many ways to define extreme weather events (Klein Tank et al., 2009), and usually they underline rare occurrence or strong impact and threat. Here we investigate extremes related to precipitation i.e. dry or wet events. We define two types of indices (Table 2) which have large impacts on society:

- Drought Spell (DS15): A drought spell is defined here as at least 15 consecutive days (at the same location) with a precipitation rate below the first percentile (very low rain). Thus it represents a threat for water resources, because of long lasting dry condition. The unit of this index is a number of days, but it is usually expressed as the ratio of days included in a drought spell during each month or season.

- Daily Extreme Precipitation (PR99): This is the occurrence of daily precipitation exceeding the value of the $99^{\text {th }}$ percentile. This type of events can trigger flash flood and is typically associated with local conditions, like stationary mesoscale convective systems, or tropical cyclone activity.

Both indices are computed for each grid cell over land only, where where droughts and flood affect the water resources and society. Thus we obtain a spatial distribution for both indices DS15 and PR99. In the following analysis, we will also consider regional averaging 
(sections 3 and 4) with the regions defined in section 2.1.1. Even if the computation implies the use of daily rainfall, we average and present the results for monthly means. Also note that for DS15, the number of occurrences is the number of days included in DS15 events. For instance, if a location has 17 consecutive dry days, it will be considered as one drought event, but the number of occurrence will be considered as 17 . So when talking about the frequency of DS15, it underlines the frequency of days included in DS15 events. For PR99 there is no such ambiguity because one event correspond to one day.

One may argue that the indices defined above are not that extreme, and can occur several times a year. Indeed, we chose indices that can be threatening but with a level of occurrence high enough to compute significant statistical analyses. Very extreme events (occurring only analysis, or would be more appropriate for a case-study, which is not the orientation of this

139 paper.

The values of the percentiles used as thresholds for each index is based on the observaolds to compute the DS15 and PR99 indices respectively, in both models and observations.

\subsubsection{Observations}

Because we need daily high resolution precipitation observations with a time coverage long 
dataset (Yatagai et al., 2009, 2012). This ground-based observational dataset has a spatial resolution of $0.5^{\circ}$ and covers the Asian monsoon area with daily output between 1951 and 2007. To be consistent with the model output, we only consider 30 years, from 1976 to 2005. Another observational precipitation dataset to compare with APHRODITE is also used, based on satellite measurements: PERSIANN (Precipitation Estimation from Remote Sensing Information using Artificial Neural Network, Sorooshian et al. (2000)). This is a daily $0.25^{\circ}$ resolution product, and we use the 1983-2014 period. In the following, APHRODITE and PERSIANN datasets will be noted APHRO and PERS respectively.

To analyze the atmospheric dynamics associated with extreme indices, the NCEP NCAR Reanalysis (Kalnay et al., 1996) is used, with a $2.5^{\circ}$ resolution, during the same period as APHRO (1976-2005) for the following variables: wind at $850 \mathrm{hPa}$ (Wind850), atmospheric surface temperature (TAS) and pressure at sea level (SLP). The observed sea surface temperature (SST) is also extracted (1976-2005) from the HadISST dataset (Rayner et al., 2003).

\subsubsection{Models}

Along with the observations, we use two high resolution GCMs: the Hadley Centre Global Environment Model version 3 - Global Climate version 2 (HadGEM3-GC2, Williams et al. (2015)) developed by the Met Office (UK), and the High Resolution Atmospheric Model with a cubed-sphere grid containing $192 \times 192$ cells on each of its six faces (HiRAM, Lin (2004); Putman and Lin (2007)) developed by the GFDL (USA). HiRAM model setup follows that in Chen and Lin (2012). Both models have a similar horizontal resolution of about $0.5^{\circ}$ in the atmosphere (HiRAM uses a cubed-sphere grid of $50 \mathrm{~km}$ horizontal resolution, corresponding to approximately $0.5^{\circ}$ resolution). The main difference is that HadGEM3GC2 includes full coupling with an ORCA025 ocean model, a $0.25^{\circ}$ version of the NEMO (Nucleus for European Modelling of the Ocean) model (Barnier et al., 2006), while HiRAM 
is an Atmospheric Global Climate Model (AGCM) forced by HadISST. Thus, HiRAM is forced by the observed variability of the SST, while HadGEM3-GC2 has a variability of its own. This will be an interesting point to consider when analyzing the dynamical patterns associated with the variability of the extreme indices. Both model runs include all forcings such as variations in solar radiation, volcanoes and aerosols.

Finally, we also include an ensemble mean of 30 models from CMIP5 (detailed in Table 4), which is used as a reference for comparison between low and high resolution GCMs. These have typical atmospheric resolutions of $1-3^{\circ}$. All datasets are summarized in Table 3 (and Table 4 for CMIP5) along with their notations.

\section{Characteristics of extreme events and their representation in the models}

In the following sections we present the characteristics of the extreme indices in the observations, and evaluate how they are reproduced in HadGEM3, HiRAM and the CMIP5 ensemble.

3.1 Seasonal signal

We first consider the mean seasonal signal of each extreme index and mean precipitation, averaged over the SC and NCK regions (Fig. 2). To compute these signals, annual percentiles are used. It means that the same threshold is used for each month to detect extreme events. Thus, the differences between dry and wet months is highlighted. Note that seasonal percentiles are considered later, in section 3.2, to analyze spatial patterns.

In the NCK region (upper row) the mean precipitation signal is similar in APHRO and PERS, and is well represented by the models. The shape of PR99 signal is also well captured by each model, including CMIP5, but with a too strong intensity during summer. The DS15 
signal is higher in PERS than in APHRO, especially during winter. HG3 follows the APHRO signal with good agreement whereas HRC is closer to PERS. Thus, both models have a realistic signal for this index, given uncertainties associated with rainfall observations. On the other hand, the mean for CMIP5 is too low, and there is a large ensemble dispersion (gray shading), it is thus difficult to estimate the quality of the mean solution.

In the SC region (lower row), the mean precipitation and PR99 are less well captured by the models: HG3 is too wet compared to APHRO, especially during summer, while HRC has a dry bias during this season. However, PERS also has a stronger signal, especially during summer. Thus the wet bias of HG3 is still within the range of the observational uncertainties. The CMIP5 mean tends to be close to APHRO but the ensemble range is large. The differences for DS15 are larger. The APHRO and PERS observations are markedly different during winter, PERS being much drier. HG3 has a low bias for all months compared to both observations. In contrast, HRC is close to PERS. The CMIP5 ensemble mean is closer to APHRO but again the spread is large.

It is clear that the models can capture the seasonal signal of both extreme indices and mean precipitation. Though the models still have wet or dry biases, they are overall within the range of observational uncertainties between APHRO and PERS). In contrast, the large spread seen for the CMIP5 models for the extreme indices DS15 and PR99 makes the ensemble solution difficult to interpret.

\subsection{Spatial distribution}

In this section, the spatial pattern is considered for each index. The results are averaged over two periods: winter (DJF) in Fig. 3, and summer (JJA) in Fig 4. All indices are expressed as a ratio of days (for instance, a ratio of 1 would mean that $100 \%$ of the days are considered 
as extreme events). We also add the mean precipitation signal (left column), this variable being expressed in mm.day ${ }^{-1}$. Boxes representing NCK and SC defined in section 2.1.1 are also shown on Fig. 3 and Fig 4. To have a better look at the spatial patterns and reduce the seasonal differences of each extreme, we now use seasonal percentiles (defined from the distributions for the 30 years of each period, e.g. winter or summer). Thus, it means that the thresholds for summer or winter are different.

During winter (DJF, Fig. 3): The mean precipitation is mostly confined to the SC region, with a clear pattern visible for APHRO and PERS, while the NCK region experiences drier conditions. The models are able to represent correctly the spatial patterns, although HG3 overestimates the amount of rain over SC compared to the observations. All models tend to be too wet in the southern part of the Himalayan region (North India). In mountainous regions, orographic effects may be difficult to represent correctly in the models. But the observations may also be biased in these regions, because of sparse networks and difficulties in catching very local rainfall. The signal of PR99 is very similar to the mean precipitation, and models have the same wet biases over the Himalayan region. In the observations DS15 has a strong level of occurrence over the NCK region. In PERS the area of frequent occurrence of DS15 events is larger than in APHRO and encompasses a large fraction of the WC region. This highlights again the uncertainties in capturing this index, depending on the observational method. Satellite datasets may have more difficulties to catch very light precipitation (thus overestimating dry days) and miss short rainfall events (that occurs between two times of measurement), but APHRO gauge network is sparse over central and East China, especially in mountainous regions. Thus its estimation of rain may be biased due to interpolation between stations. HG3 and HRC can both simulate similar spatial distributions compared to APHRO. HRC is also drier over SC, but it is consistent with PERS. As for the CMIP5 
ensemble, it can capture the spatial pattern of this index, but with much lower intensities. The impact of orography (the Himalayas) on the circulation may be less easily captured by the low resolution models, as illustrated by the strong bias in the CMIP5 ensemble.

During summer (JJA, Fig. 4): Asia is subject to wetter conditions compared to DJF, as shown in the mean precipitation signal. Only the WC region remains drier. There is good agreement between the spatial patterns seen in the observations and in the models, but in CMIP5 the signal is too weak. In the observations, PR99 shows a clear band over East Asia, from SC to the eastern part of NCK and Japan. The signal is stronger in PERS than in APHRO. It shows that satellite observations tend to estimate larger heavy rainfall events, and lower light rainfall (as described in the previous section). Thus, there is a range of uncertainties between ground data and satellite data. The shape of the signal is captured by HG3 and HRC, but compared to observations the signal extends too far north. The high resolution models capture the signal more accurately than the CMIP5 ensemble, especially over the Himalayan region. For DS15 only a weak signal is seen in observations over the western part of China for the PERS dataset. HG3 does reproduce this pattern well, but HRC and CMIP5 both have a large dry bias over this region. When looking at the distribution (pdf) of precipitation (result not shown), HRC can reproduce similar light precipitation compared to the observations. Thus the differences observed for DS15 come more from the long lasting condition (15 consecutive days) used for this index. HRC may produce more easily consecutive dry days (with rain below the threshold used to detect light rain), and raining days may be grouped at the beginning or end of the period, while in the observations raining days are scattered during the whole period. We point out here a limitation in the definition of this index, because of its sensitivity to single rainfall events. However, in the regions of concern 
(NCK and SC), results are more consistent between the observations and models, thus it won't affect our analysis below.

All models can capture the mean precipitation and extreme patterns during each season, but CMIP5 has more difficulties to represent correctly the intensity and the spatial distribution of extreme indices. HRC also exhibits a dry bias over WC during summer. If we focus on the two sub-regions of interest (SC and NCK) the two high resolution models have a more accurate representation of DS15 during DJF and of PR99 during JJA, compared to CMIP5. The differences between APHRO and PERS illustrate how the estimation of extreme events can drastically change according to the measurement methods used (satellites or ground stations). Thus the bias identified in the models should be considered carefully and results from HRC and HG3 are overall within the range of the observational uncertainties.

To summarize the results of the previous sections (3.1 and 3.2), we use a Taylor diagram (Taylor, 2001) to represent the scores of models (Fig. 5) in comparison with APHRO. We use only one observational dataset here, but we have to keep in mind that differences exist with PERS, thus the reference used for Taylor diagram could be different with another dataset. In the figures, normalized standard deviation (NSTD) represents the agreement in the magnitude of the spatial variation of the signals, while the correlation indicates the agreement between spatial patterns. NCK and SC are shown in the left and right panels respectively. Colors are used to identify different variables. Given the strong seasonal variation of each index, we consider the mean scores during DJF and JJA and we only show the results for each index when they have the highest level of occurrence (DJF for DS15 and JJA for PR99). Mean precipitation is shown for both seasons.

Both models can capture more easily the signal in NCK (left plot). HG3 has especially good skills in correctly simulating the spatial distribution of precipitation and each of the 
indices over this area, with correlation above 0.8 . It can also capture the magnitude of spatial variation with good quality (all NSTD are very close to 1), except for mean precipitation during winter. HRC also has good performance in simulating spatial patterns but with a lower correlation for PR99. CMIP5 has similar skills for mean precipitation, but extreme indices have too low NSTD.

In the SC region (right plot), the models have lower skills in capturing the signals. HG3 has a too large magnitude of spatial variations except for DS15. HRC has better scores in terms of magnitude of spatial variations but with lower correlations. CMIP5 still has good results for mean precipitation, but the score for DS15 and PR99 are too low, both in terms of NSTD and correlations.

As illustrated in Figs. 3 to 5, both high resolution models exhibit better skill in simulating good spatial patterns (correlation) than the magnitude of the signal (NSTD), and are better in NCK than in SC. The results in the high resolution models HG3 and HRC are significantly improved compared to the low resolution CMIP5 ensemble. Increasing the resolution of the models is not enough to solve all the problems for estimating extreme events, but the higher resolution models used in this study have an improved ability to reproduce heavy rainfall intensity closer to that in the observations. Moreover, they have the advantage of giving a unique solution that is more easily interpreted. Indeed, when using an ensemble such as CMIP5, the mean solution should always be associated with the ensemble uncertainties (i.e. the spread of the ensemble), that may be large and lead to complex analysis when using cross-variable analysis such as we will perform in section 4 . This problem is avoided when using a single model solution, even if this solution presents some bias. The biases observed in HG3 and HRC may be due directly to the parameterization and convection schemes, or due to errors in simulating the dynamics. We explore this point later in section 4 , by investigating how the large scale dynamics is linked to each extreme index sig- 
nal. But we also have to keep in mind that large differences can exist between APHRO and

PERS observations, especially when looking at extreme indices, thus the biases identified in the models should be considered carefully and results from HRC and HG3 are in the range of the observational uncertainties.

3.3 Interannual variability of extreme indices

Here we investigate the variability of each extreme index in NCK and SC. We compute the 30-year mean and the monthly variability (each month of each year is averaged individually) of occurrences of DS15 (PR99) during DJF (JJA). The variability is approximated by 2 standard deviations ( 1 standard deviation above and below the mean). We also compute the interannual variability of the seasonal means (each season of each year is averaged individually). Results are summarized in table 5.

The monthly variability of DS15 is overall about twice the mean in SC, and of the same order as the mean in NCK. It illustrates how large the variability of extreme events can be. The models can reproduce this signal, though the mean and variability are too low in HG3 in SC, and too high in HRC. These biases correspond to the wet and dry biases mentioned in the previous sections. For PR99, both monthly and interannual variabilities are lower, all values being close to 0.02 . The models have good skill at reproducing mean and variability signals for each region.

The interannual variability is estimated here to be about the same order as the monthly variability. However, this is due to our approximation of the variability as being equal to 2 standard deviations. When looking at the monthly signal, high and low peaks in PR99 or DS15 can be observed (in both the observations and models). It means that specific months can coincide with a large number of extreme events, but these peaks are too rare to impact 
the monthly standard deviation of the total signal. The interannual variations are also characterized by some peaks, but with lower amplitude. Both models have overall good skills in capturing the main characteristics of the signal.

A specific point to consider is the tropical cyclone (TC) activity during summer. Depending on the ability of models to simulate TCs, it could lead to a bias in the extreme indices during JJA, especially for PR99 in SC. However, an investigation of the occurrence of TCs is beyond the scope of this work, thus we consider TCs as a part of the uncertainties associated with the results.

The variability of extremes is significant compared to the mean signal. Thus it raises the question of what can impact the occurrence of extreme events and what can lead to specific months (or years) being prone to extreme weather conditions? It is especially important to understand the conditions associated with these extremes in the current climate to anticipate how this variability could be affected in a changing climate.

\section{Dynamical control of the variability of extreme events}

We saw in the previous section that the variability of extreme indices can have a significant impact. It is thus important to understand what controls this variability. Because these indices are related to precipitation, an initial assumption would be a control by the moisture content in the atmosphere. However the atmospheric circulation may also play a role, by advecting humid air masses from the ocean or dry air from the continent for instance. We will attempt here to identify the main control patterns in several dynamical atmospheric variables, using a composite and correlation approach.

We first compute the correlation between each index (DS15 and PR99) and different monsoon indices that describe the monsoon circulation (e.g. Jhun and Lee (2003), Wang 
et al. (2008) or Wang and Chen (2014)). As we study indices during two seasons, there are two seasonal monsoon signals to investigate: the winter monsoon and the summer monsoon.

We selected three different indices, all computed from the wind field, that cover different aspects of the monsoon circulation. These indices are based on the papers cited above and defined as follows (brackets indicate regions of averaging):

\section{- East Asia Summer Jet:}

$$
\operatorname{EASJ}=U_{200}\left(30^{\circ}-50^{\circ} N, 110^{\circ}-140^{\circ} E\right)
$$

This index represents the strength of the $200 \mathrm{hPa}$ Jet (zonal wind speed component), which weakens and moves northward during the onset of the East Asia summer monsoon.

- West North Pacific Summer Monsoon:

$\mathrm{WNPSM}=U_{850}\left(5^{\circ}-15^{\circ} \mathrm{N}, 100^{\circ}-130^{\circ} E\right)-U_{850}\left(20^{\circ}-30^{\circ} \mathrm{N}, 110^{\circ}-140^{\circ} E\right)$.

This index illustrates the zonal wind shear at $850 \mathrm{hPa}$ that develops in the North West Pacific region during the summer monsoon.

- East Asia Winter Monsoon:

$\mathrm{EAWM}=U_{200}\left(27.5^{\circ}-37.5^{\circ} \mathrm{N}, 110^{\circ}-170^{\circ} \mathrm{E}\right)-U_{200}\left(50^{\circ}-60^{\circ} \mathrm{N}, 80^{\circ}-140^{\circ} \mathrm{E}\right)$.

This index is linked to the thermal and pressure contrast between the Siberian region and the North West Pacific. It is a good indicator of the winter monsoon signal. Note that it is defined with $300 \mathrm{hPa}$ zonal winds in Jhun and Lee (2003) but here, due to data availability, we use the $200 \mathrm{hPa}$ wind, which is still consistent.

The three monsoon indices are illustrated in Fig. 6 for NCEP reanalysis (black line), HG3 (red line) and HRC (blue line). Though each index has been defined for a specific season (see definition above) we plot the signal through the whole year to have a clear view of the variations between winter and summer. The EASJ is well simulated by HG3, 
especially during summer time. HRC can reproduce the shape of the seasonal variation, but it has a low bias of 5 to $10 \mathrm{~m} \cdot \mathrm{s}^{-1}$. The wind shear in the North West Pacific (illustrated by WNPSM) is not as well reproduced by the models. HG3 has a good transition period between April and July, and it can simulate the break during June-July, but the index is too high during late summer. In contrast, in HRC the transition is too strong, and it reaches a maximum in June. After that, the index value decreases and is closer to NCEP during late summer. Finally, the observed seasonal variation of EAWM is well simulated in both models, but HG3 has a small positive bias during winter $\left(5 \mathrm{~m} \cdot \mathrm{s}^{-1}\right)$ and $\mathrm{HRC}$ has a low bias throughout the year (5 to $10 \mathrm{~m} \cdot \mathrm{s}^{-1}$ ). Both models simulate correctly the transition break between April and June, but with the same bias mentioned previously. The biases seen in the EASJ and EAWM indices for HRC indicate that subtropical East Asia jet in this model is too weak. This may explain the dry tendency in the model. Indeed, as shown by Li and Zhang (2008), a weak jet is related to weak precipitation over the East Asia region. The correlation between extreme indices and monsoon indices are summarized in Table 6. Bold font is used to highlight the correlation coefficients larger than 0.17 (corresponding to the 90\% confidence level when considering each month as independent).

In addition, we also compute the correlation between the monthly anomalies of the extreme indices (averaged over NCK and SC) and the monthly anomalies of the sea surface temperature (SST) and four atmospheric fields: wind intensity (i.e. absolute wind speed) at $850 \mathrm{hPa}$ (Wind850), wind intensity at $200 \mathrm{hPa}$ (Wind200), sea level pressure (SLP) and atmospheric surface temperature (TAS). These correlations give a first approximation of how the large scale dynamics is linked to the monthly variability of extreme indices (averaged over each region). For each extreme index, we also selected the months with a level of occurrence larger than 1 standard deviation (deviation from the mean) and the composites of the dynamical variables are computed using these specific months. Fig. 7 and 8 display respec- 
tively the composites of DS15 and PR99. In these figures, the regions where the confidence level is higher than $90 \%$ (based on the correlation) are displayed. The full patterns are also analysed but not shown.

The composites and correlations are also computed for the interannual variability, using seasonal anomalies instead of monthly anomalies (Table 7, Fig. 9 and 10).

4.1 Monthly variability

We first investigate the monthly variability (Table 6, Figs. 7 and 8).

DS15 (Fig. 7) is mostly characterized by large positive anomalies of TAS over the northern part of the continent. This anomaly is visible in the observations and both models. Corresponding to the near surface high temperature anomaly, low pressure anomaly occurs in the high latitude Northeast Asia. The westerly (wind850) is likely strengthened from Siberia to the North-East Asia region corresponding to the pressure and temperature anomaly pattern. The downstream northwesterly anomaly furthermore is related to an increase of the dry air transport and drought over NCK (Fig. 7, left column). On the other hand, associated with the drought over SC, the increase of the lower-tropospheric north-westerlies is also marked near the border between the high and low pressure anomaly; these circulation and pressure anomalies occur relatively southward over the coastal region of East Asia and also favour the southward dry air transport. Besides, the enhanced upper-tropospheric westerly is likely also related to the land-sea pressure contrast. Overall, composite of DS15 are mainly characterized by strong positive anomalies of TAS and winds over the continent; and both models can reproduce the patterns. A speculation is that in a warming climate the polar regions warm faster, and the consequently induced a series changes of the atmospheric condition which favour more extreme DS15 during winter of East Asia. We also find that the signal on SST 
is less clear, with only a negative anomaly over the equatorial Pacific and positive anomaly over the North-Eastern Pacific, which is a typical La-Niña pattern. It is mostly visible in APHRO and HRC (that use the same SST forcing), but not in HG3. The correlation between DS15 and the winter monsoon index EAWM (Table 6) are non-significant. It indicates that using this index is not enough to link the monsoon circulation to the occurrence of extreme dry events.

The composites for PR99 (Fig. 8) show clear patterns over the oceanic region. In APHRO, large positive anomalies of SST over North-East Pacific and India Ocean and East Pacific (for SC) indicate an increase in moisture sources. These positive SST anomalies are also visible in the models but with less confidence. Along with the SST anomaly, a clear positive SLP pattern (for NCK) also covers most of the North Pacific. It corresponds to a strengthening of the Pacific High. As a consequence, wind850 is strengthened along the coast of East Asia, corresponding to an enhanced summer monsoon circulation (and an increase of the moisture transport from the southern ocean to East Asia). We also note a significant negative wind850 anomaly in HRC over the Bay of Bengal Peninsula. In this model, the SLP patterns over East Asia are larger, which suggests a stronger response of the atmospheric circulation. Thus, the increase of southerlies along the coast of East Asia is even stronger, but the westerlies from the Indian Ocean are reduced. The correlations between PR99 and both summer monsoon indices are weak (Table 6) and sometimes in contradiction between observations and models. Given the complexity of the composite patterns, using monsoon indices based on averaging over large region is not enough to catch the signal. In this case, a spatial (composite) analysis is more appropriate.

The variability of PR99 is mostly associated to ocean SST and SLP anomalies, i.e. moisture sources and transport. Once again, this supports the idea that in a warming climate, 
conditions triggering extreme precipitation over East Asia could become more frequent (because of the warmer SST). But the transport (wind850) has also a significant role, as illustrated by the composites, and could enhance or reduce the effect of the SST, depending on how the atmospheric circulation would react to global warming.

The previous results illustrate the different anomaly patterns associated with DS15 and PR99 variability. The first is driven by continental temperature and pressure, while the second is more related to ocean temperature and pressure. In both cases, the low level monsoon circulation is enhanced. There is good agreement between observations and models, though some differences in patterns and confidence levels exist. However, the monsoon indices do not have a correlation with extreme indices. This suggests that these types of indices are not easily linked to the variability of extreme events, at least not in the way we have defined them.

Another point is that tropical cyclones may play a role in the variability in PR99. Because in our analysis we didn't separate the contribution from TCs, this may impact the results of our correlations and lead to patterns that are less clear. Nevertheless, a clear signal is identified in the large scale circulation. This means that the TCs are not the only factor responsible for extreme precipitation variability in East Asia and that the monsoon circulation also plays a significant role in modulating these extremes.

\subsection{Control of the Interannual Variability}

We now focus on the interannual variability controls (Table 7, Fig. 9 and 10). Though this variability is lower in terms of magnitude, it can still significantly enhance or reduce extreme event occurrences from one year to another. 
The composites for DS15 (Fig. 9) are less clear compared to ones based on the monthly variability (Fig. 7). The confidence levels are overall below $90 \%$ making these results less significant. It is still possible to identify positive patterns of TAS and wind 850 over continent in the models, especially for HRC (bottom panel). The HRC model shows a strong control of the continental temperature for DS15 in SC, which may explain its tendency to be drier than observed in SC (section 3). Correlations with the winter monsoon indices are also nonsignificant (Table 7).

Because we used only 30 years of data, and computed interannual variability based on seasonal means, a clear signal may be less easy to detect. Using longer periods would be more suitable for such an analysis.

PR99 composites (Fig. 10) exhibit strong and confident patterns of positive SST over the Pacific, in the observations and models. It is a clear indication that the ocean temperature (and the source of moisture) is the main driver of PR99 interannual variability. In addition, HRC shows similar patterns of SLP and wind850 (compared to monthly variability), i.e. the strength of the Pacific High. Once again, the atmospheric response is stronger in this model than in the observations. This illustrates the importance of air-sea interaction and the sensitivity to SST forcing. Correlations with the summer monsoon indices tend to be negative (Table 7), especially for WNPSM. But given the composite analysis, it is clear that the wind patterns should be considered carefully, and that the monsoon indices may not be appropriate to provide a clear view of the real mechanisms.

In terms of interannual variability, it is difficult to have a clear conclusion about DS15 variability control. On the other hand, PR99 variability is clearly linked to ocean temperatures, with significant relationships found in both observations and models. A warmer SST is, not surprisingly, expected to favour PR99 events over East Asia. But in contrast to the monthly 
variability, the monsoon circulation does not exhibit a strong signal in terms on the interannual variations. This illustrates the different mechanisms that can impact extreme events, depending on the timescales.

\section{Summary and Discussion}

In this paper we investigate two types of extreme weather events related to precipitation: drought spells (DS15) and daily heavy rainfall (PR99). We focus our analysis on continental East Asia, a region heavily populated and thus threatened by such weather events. We separate the East Asia region in two main sub-regions: North China and Korea (NCK) and South China (SC). The objective is to investigate the possible large scale atmospheric conditions that can impact the variability of these extremes.

Two high resolution models are analyzed, one is an AGCM (HiRAM, HRC) and one is fully coupled to an ocean model (HadGEM3-GC2, HG3), and we first validate their performance (in comparison with two observational datasets: APHRODITE and PERSIANN) in section 3. An ensemble of models from the CMIP5 is also used for comparison. Both high resolution models exhibit good skills at representing extreme events over East Asia and are more accurate than the CMIP5 ensemble (comprised of lower resolution models) in reproducing spatial patterns. They can also capture the seasonal and interannual signals of each extreme index. Dry and wet bias are identified in SC region for HRC and HG3 respectively. This behaviour is a common problem in many models, as shown by the scattering of the CMIP5 ensemble over SC. Models typically have more difficulties to realistically represent the observed signal over this region and it makes the analysis more sensitive. We also point out that, depending on the observational method (satellite or ground station), the estimation 
of precipitation is different. Overall, the both high resolution models have results within the range of observation uncertainties.

\section{The dynamical impact of the atmospheric circulation on the variability of extremes is then} investigated. Both monthly and interannual variabilities are considered, using only the seasons with the highest occurrence of each extreme (DJF for DS15 and JJA for PR99). In order to assess the relationship between extremes and atmospheric large scale circulation, spatial correlations and composite analyses are used with several dynamical fields (Wind850, Wind200, TAS, SLP) and SST.

The monthly variability of extremes, which is also the larger in terms of intensity, has a clear positive correlation with the local wind intensity, meaning that a local modulation of the monsoon circulation directly impacts the occurrence of extremes. TAS over the northern part of the continent also has a positive impact on DS15. The models can reproduce these signals and thus support the conclusion made from observational results. This shows that the variability of extremes in East Asia is strongly influenced by local winds, but also by thermal and pressure land-sea contrast. A significant correlation with SST is also found in the observations for PR99, indicating that the ocean state (and, by extension, the moisture source) can significantly affect the short-term variability of these extreme events. However, models results for SST are less clear and may reflect the difficulty in correctly representing the strength of air-sea interactions in the models (either fully coupled or forced by prescribed SST).

When looking at the interannual variability (section 4.2), the large scale conditions have less significant impact on DS15. The only clear and significant control is found in HRC for SLP and TAS, but it may be linked to the fact that this model is forced by prescribed SST, 
so that the atmospheric response is more pronounced. On the other hand, PR99 variability

is linked to a positive SST influence, in both the observation and models.

We also use monsoon indices (EASJ, WNPSM and EAWM, see definition in section 4) and compute correlations with each extreme index to compare with the spatial analysis results. Using this method does not provide convincing conclusions, and sometimes the results from the models are in contradiction with those from the observations.

With our analysis, we showed that extremes in East Asia are strongly related to the temperature over the continent and the monsoon circulation in terms of monthly variability, and to the ocean temperature in terms of interannual variability.

A common assumption for future projections of the climate is that an increase in atmospheric moisture could favour an increased frequency of extreme events. However, here we show that the changes in large scale circulation could also have a significant impact in controlling these events, especially because the continental temperature is expected to increase faster in a warming world and would lead to an increase in the land-sea contrast. There are also some indications that the northern part of Siberia would have a strong impact on extremes in Asia. Because this region is very sensitive to any change in global temperature, it raises the question as to what extent it could affect the occurrence of extremes over tropical regions in future projections. The changes in dynamics and their impact on extremes should be investigated with high resolution models in future work. 


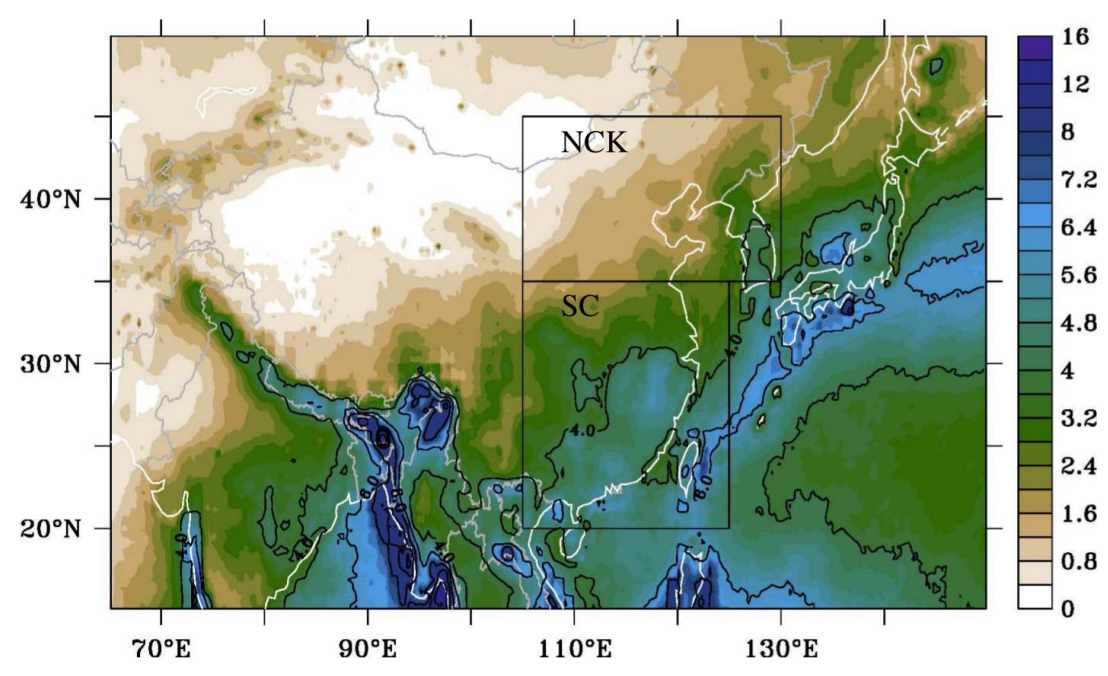

Fig. 1 1998-2013 climatology of precipitation (shading, in mm.day ${ }^{-1}$ ) from TRMM observations (Huffman et al., 2007) over East Asia. Black countours highlight precipitation above $4 \mathrm{~mm} \cdot \mathrm{day}^{-1}$ and are plotted every 2 mm.day ${ }^{-1}$. The black rectangles refer to the 2 regions defined in the Table 1: North China-Korea (NCK) and South China (SC). 

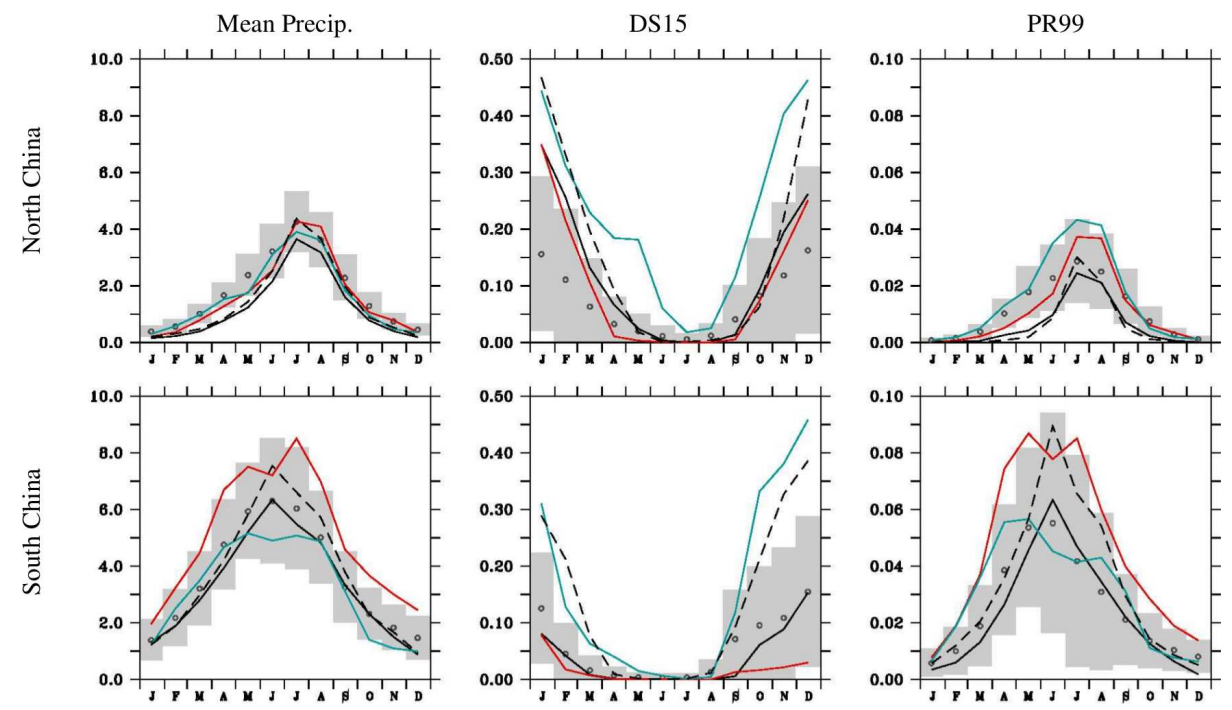

Fig. 2 Seasonal signal of mean precipitation and of each extreme index (from left to right: Mean Precipitation, DS15 and PR99), averaged over North China-Korea (top row) and South China (bottom row) regions (defined in Fig. 1). Results are displayed for observation (APHRO: black line and PERSIANN: black dashhed line), HG3 (red line) and HMC (blue line). CMIP5 ensemble mean is represented by black circle symbols, and the grey shading indicates 1 ensemble standard deviation around the mean. All values are expressed as a ratio of days (thus a value of 0.3 means that $30 \%$ of the days during a month are considered as extreme), except the mean precipitation that are in mm.day ${ }^{-1}$. 


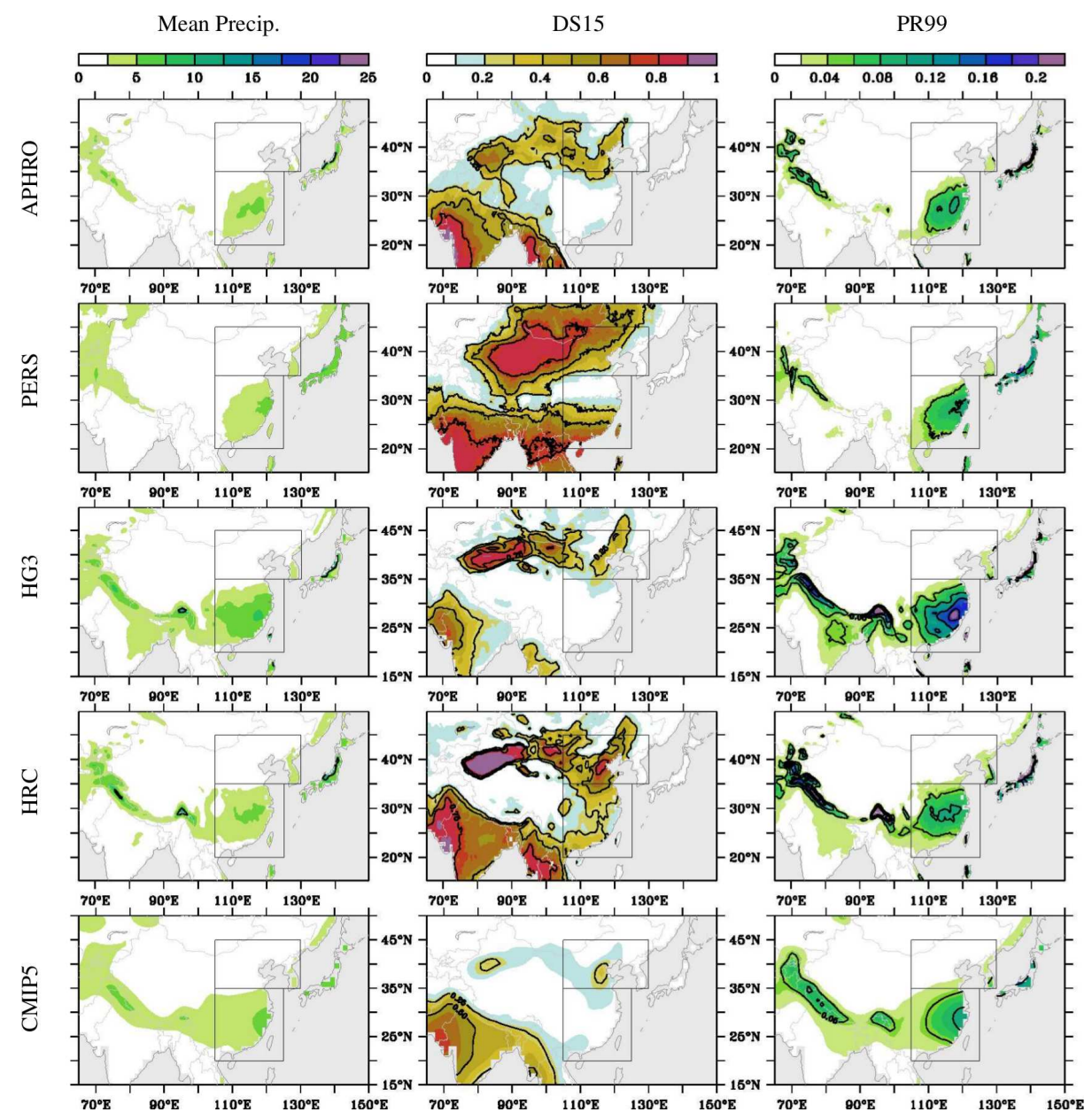

Fig. 3 Mean precipitation and extreme indices during DJF, for (top to bottom row): observation (APHRO), observation (PERSIANN), HG3, HRC and CMIP5 ensemble mean. Black boxes indicate NCK and SC as defined in Fig. 1. Units are in mm.day ${ }^{-1}$ for mean precipitation, and ratio of days for all other variables. Black outlines highlight mean precipitation every $6 \mathrm{~mm}_{\text {day }}{ }^{-1}$, DS15 every 0.25 and PR99 every 0.05 . 

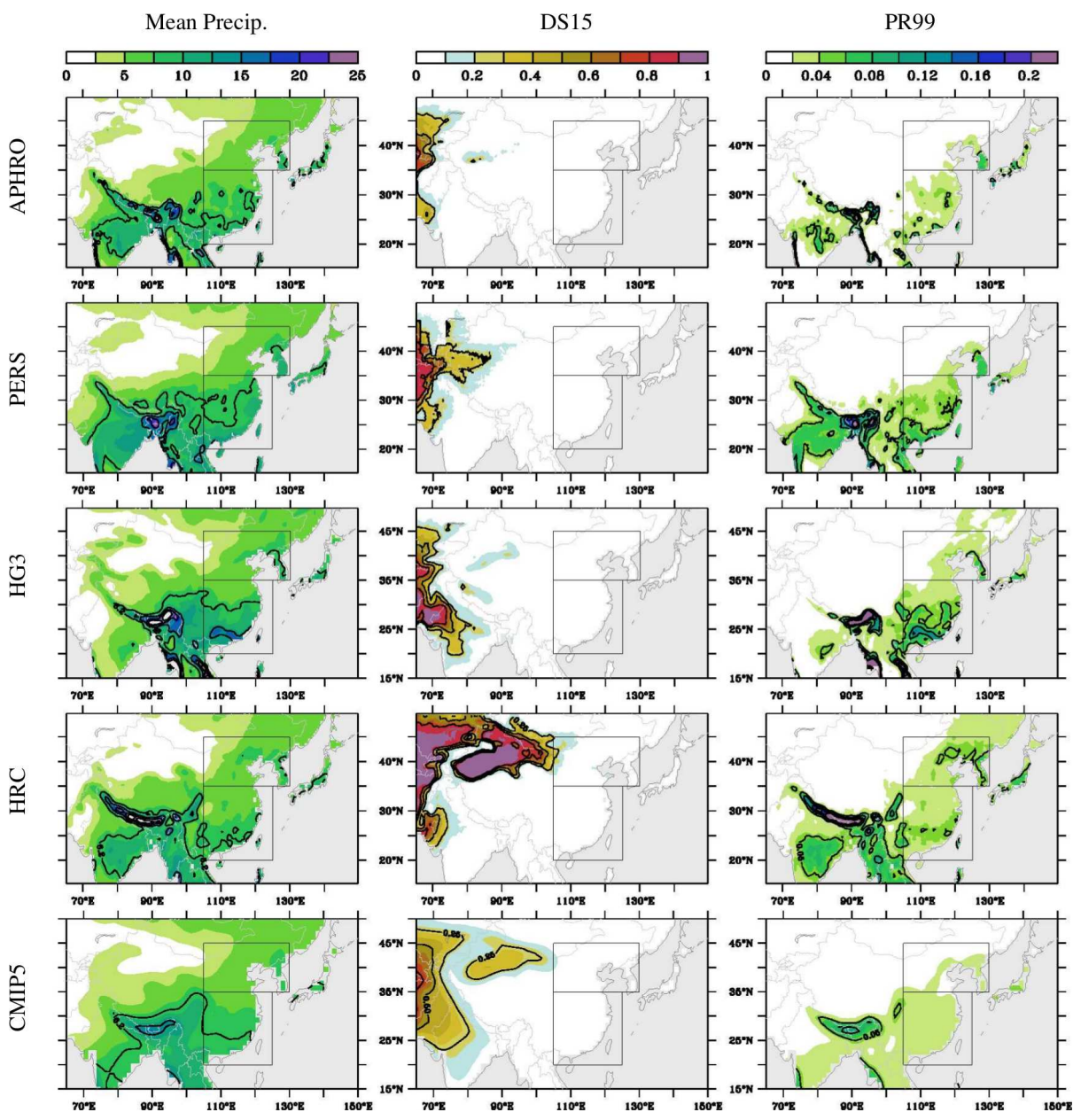

Fig. 4 Same as Fig. 3 but for JJA. 

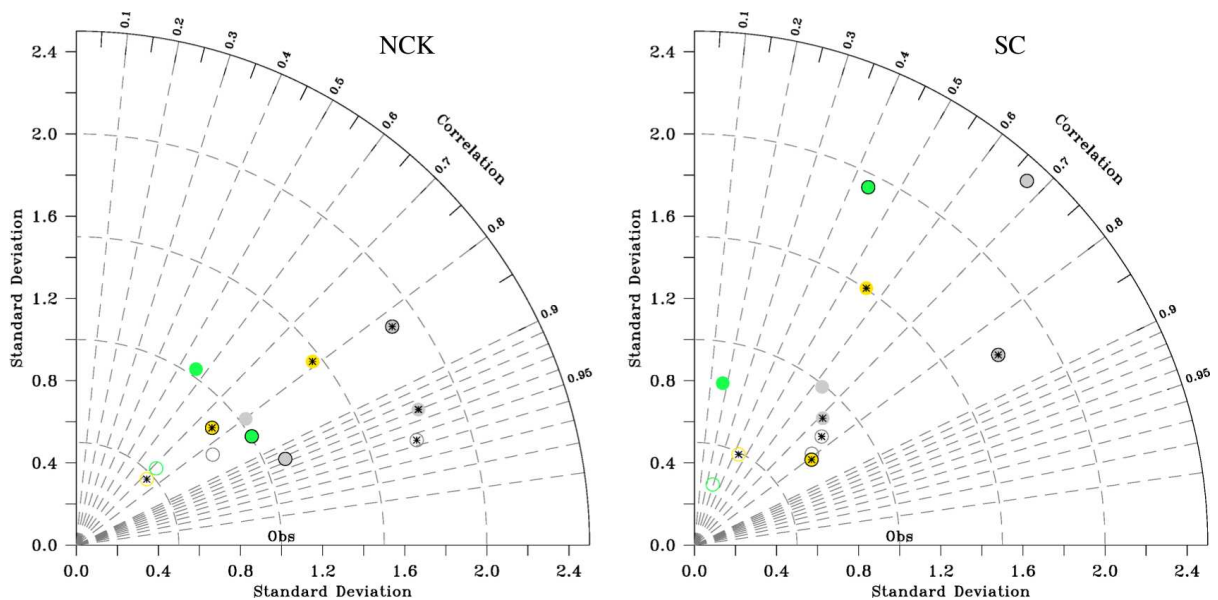

Fig. 5 Taylor diagrams of mean precipitation and extreme indices for North China-Korea (left) and South China (right). Colors indicate the different variables: mean precipitation (gray), DS15 (yellow) and PR99 (green). HG3 (and HRC) model results are represented by the shaded circles with (and without) contours, whereas the CMIP results are represented by the empty circles (ie not shaded but with contours). Two periods are separated: DJF (symbols with stars inside) and JJA (symbols without stars inside). The reference point corresponds to APHRODITE observation (Obs) and is indicated at 1 standard deviation and correlation.
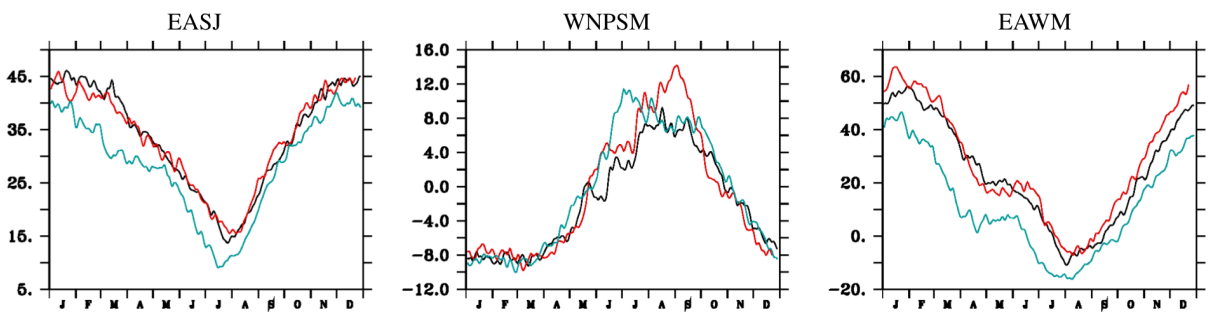

Fig. 6 Monsoon index in NCEP reanalysis (black), HG3 (red) and HRC (blue) averaged during historical period (1976-2005). Indices are, from left to right: EASJ, WNPSM and EAWM (see definition in the text, section 4). All values are in $\mathrm{m} \cdot \mathrm{s}^{-1}$. 

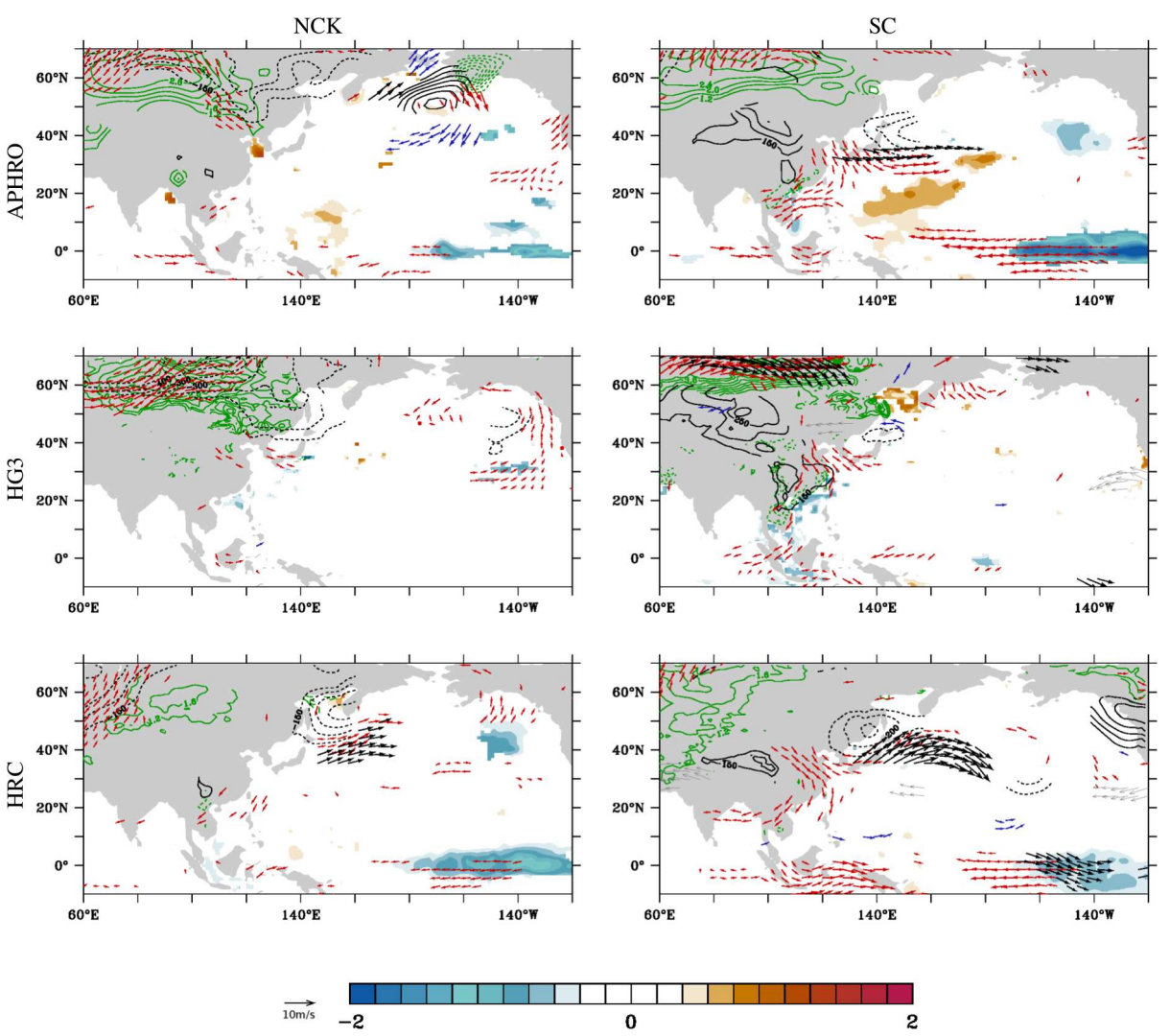

Fig. 7 Composite of each dynamics field for months with strong DS15 occurrence, in North China-Korea (left) and South China (right). Composite are displayed from top to bottom row for: APHRO (and NCEP reanalysis for dynamical field), HG3 and HRC. Dynamical variables are represented with: red and blue vectors (positive and negative anomalies of wind850), black and gray vectors (positive and negative anomalies of wind200), full and dashed black contours (positive and negative anomalies of SLP), full and dashed green contours (positive and negative anomalies of TAS), and color shading (SST). All results are above $90 \%$ confidence level (see text). 

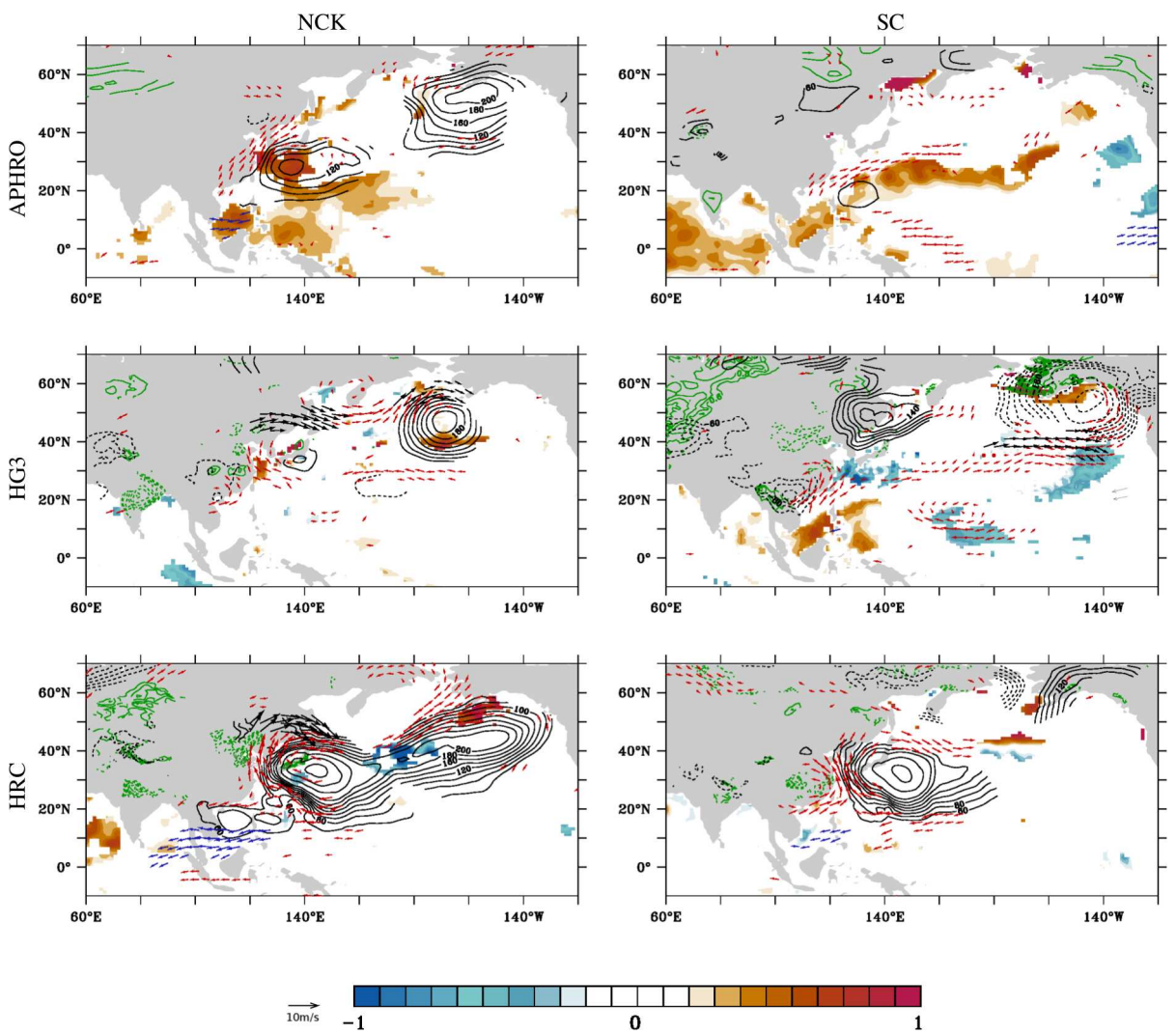

Fig. 8 Same as Fig. 7 but for PR99. 

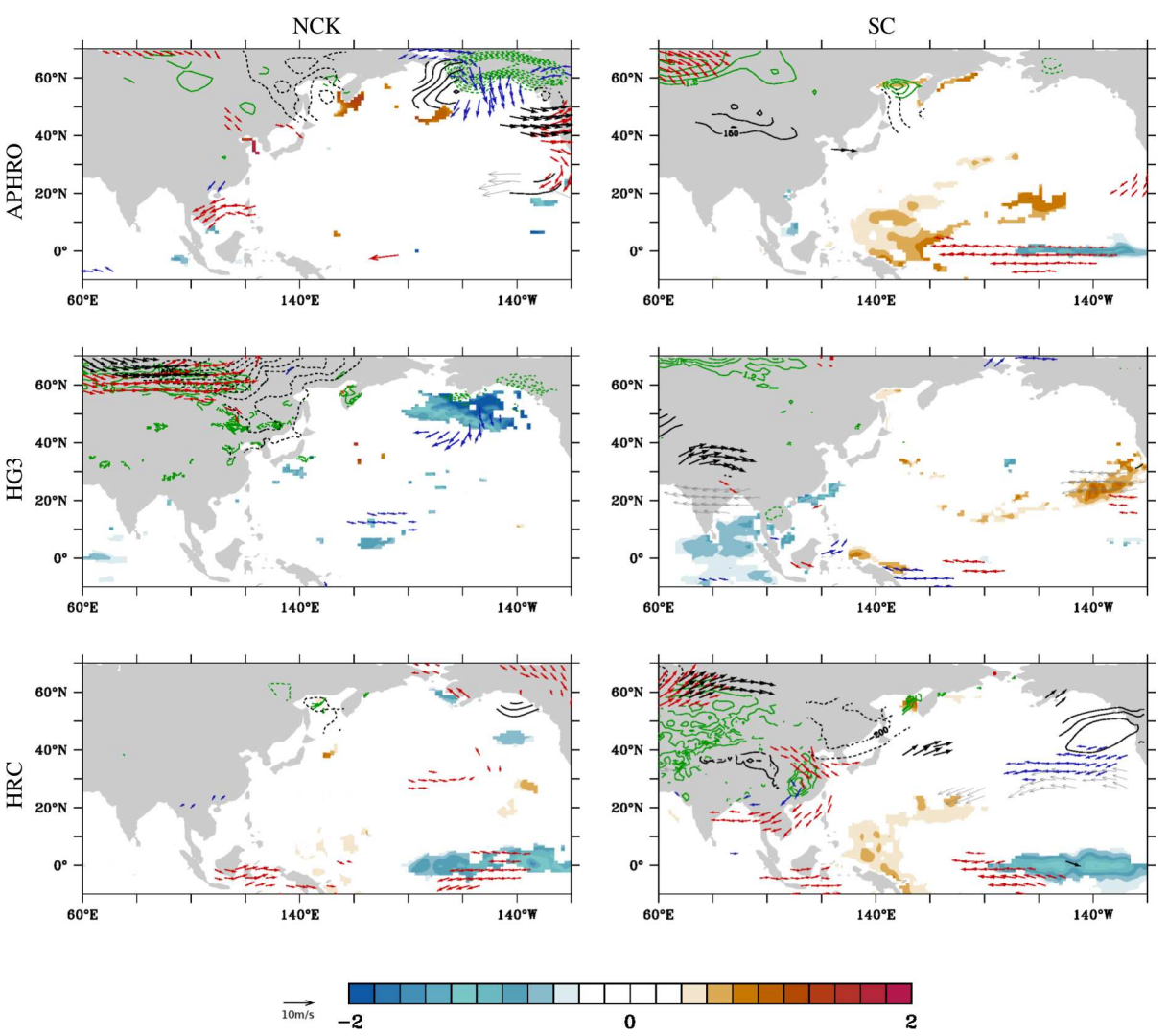

Fig. 9 Same as Fig. 7 but based on interannual variability. 

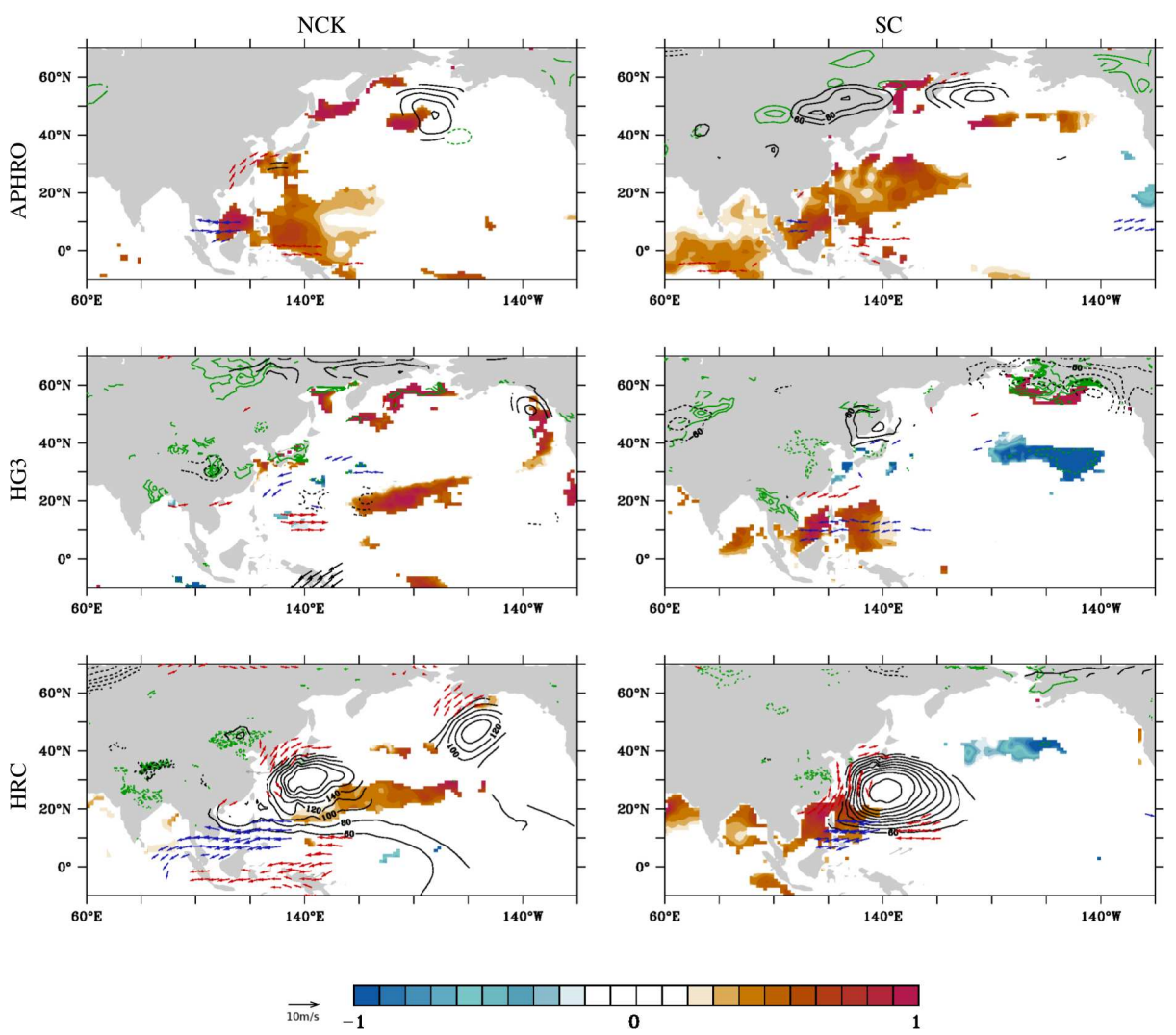

Fig. 10 Same as Fig. 9 but for PR99. 
Table 1 Definition of the China regions (Fig. 1).

\begin{tabular}{ccc}
\hline Notation & Full name & Location \\
\hline NCK & North China-Korea & 105E-130E, 35N-45N \\
\hline SC & South China & 105E-125E, 20N-35N \\
\hline WC & West China & $75 \mathrm{E}-105 \mathrm{E}, 30 \mathrm{~N}-45 \mathrm{~N}$ \\
\hline
\end{tabular}

Table 2 Description of extreme indices (see section 2.1.2).

\begin{tabular}{lll}
\hline Notation & Full name & Description \\
\hline PR99 & Daily Extreme 99 & This is the occurrence (frequency) of daily precipitation exceeding \\
& the value of the $99^{\text {th }}$ percentile. \\
\hline DS15 & Drought Spell 15 & A drought spell is defined here as at least 15 consecutive days with a precipitation \\
& rate bellow the first percentile (very low rain). \\
& We then sum all the days considered as being part of a drought spell.
\end{tabular}


Table 3 Summary of the data used.

\begin{tabular}{|c|c|c|c|}
\hline Notation & Full name & Period used & Atmospheric forcing and SST. \\
\hline \multirow[t]{3}{*}{ HG3 } & HadGEM3-GC2 Historical & Historical: $1971-2000$ & Run with historical forcing. \\
\hline & Williams et al. (2015) & & Coupled with ORCA025 (Barnier et al., 2006). \\
\hline & & & Resolution (atmosphere): $0.5^{\circ}$ \\
\hline \multirow[t]{3}{*}{ HRC } & HiRAM Historical & Historical: 1979-2008 & Run with historical forcing. \\
\hline & Lin (2004); Putman and Lin (2007) & & Forced by HadISST (Rayner et al., 2003) \\
\hline & & & Resolution: $50 \mathrm{~km}$ grid $\left(0.5^{\circ}\right)$ \\
\hline \multirow[t]{2}{*}{ CMIP5 } & Phase 5 of the Coupled Model & Historical: 1976-2005 & Ensemble run with historical forcing. \\
\hline & Intercomparison Project & & See Table 4. \\
\hline \multirow[t]{2}{*}{ APHRO } & APHRODITE Asia Monsoon & Historical: 1976-2005 & Ground station observation. \\
\hline & Yatagai et al. $(2009,2012)$ & & Resolution: $0.5^{\circ}$ over land only \\
\hline \multirow[t]{2}{*}{ PERS } & PERSIANN & Historical: 1983-2014 & Satellite observation. \\
\hline & Sorooshian et al. (2000) & & Resolution: $0.25^{\circ}$ \\
\hline \multirow[t]{2}{*}{ NCEP } & NCEP-NCAR Reanalysis & Historical: 1976-2005 & Atmospheric reanalysis. \\
\hline & Kalnay et al. (1996) & & Resolution: $2.5^{\circ}$ \\
\hline
\end{tabular}


Table 430 CMIP5 models used for this study. The resolution is given in grid points (latitude $\times$ longitude).

\begin{tabular}{|c|c|c|c|}
\hline Model Name & Institute & Country & Resolution \\
\hline ACCESS $1-0$ & $\begin{array}{l}\text { Commonwealth Scientific and Industrial Research Organisation (CSIRO), } \\
\text { and Bureau of Meteorology }\end{array}$ & Australia & $144 \times 192$ \\
\hline ACCESS1-3 & $\begin{array}{l}\text { Commonwealth Scientific and Industrial Research Organisation (CSIRO), } \\
\text { and Bureau of Meteorology }\end{array}$ & Australia & $144 \times 192$ \\
\hline BCC-CSM1-1 & Beijing Climate Center (BCC), and China Meteorological Administration & China & $64 \times 128$ \\
\hline BCC-CSM1-1-M & Beijing Climate Center (BCC), and China Meteorological Administration & China & $160 \times 320$ \\
\hline BNU-ESM & Beijing Normal University (BNU) - Earth System Model & China & $64 \times 128$ \\
\hline CanESM2 & Canadian Centre for Climate Modelling and Analysis (CCCma) & Canada & $64 \times 128$ \\
\hline CCSM4 & National Center for Atmospheric Research (NCAR) & USA & $192 \times 288$ \\
\hline CESM1-BGC & $\begin{array}{l}\text { National Science Foundation, Department of Energy, } \\
\text { National Center for Atmospheric Research (NCAR) }\end{array}$ & USA & $192 \times 288$ \\
\hline CMCC-CESM & Centro Euro-Mediterraneo per i Cambiamenti Climatici (CMCC) & Italy & $48 \times 96$ \\
\hline CMCC-CM & Centro Euro-Mediterraneo per i Cambiamenti Climatici (CMCC) & Italy & $240 \times 480$ \\
\hline CMCC-CMS & Centro Euro-Mediterraneo per i Cambiamenti Climatici (CMCC) & Italy & $96 \times 192$ \\
\hline CNRM-CM5 & $\begin{array}{l}\text { Centre National de Recherches Météorologiques (CNRM), and Centre Européen de } \\
\text { Recherches et de Formation Avancée en Calcul Scientifique }\end{array}$ & France & $128 \times 256$ \\
\hline CSIRO-Mk3-6-0 & $\begin{array}{l}\text { Commonwealth Scientific and Industrial Research Organization (CSIRO) } \\
\text { Marine and Atmospheric Research (Melbourne) in collaboration with the } \\
\text { Queensland Climate Change Centre of Excellence (QCCCE) (Brisbane) }\end{array}$ & Australia & $96 \times 192$ \\
\hline EC-EARTH & EC-EARTH consortium (11 countries) & & $160 \times 320$ \\
\hline FGOALS-g2 & $\begin{array}{l}\text { Institute of Atmospheric Physics, Chinese Academy of Sciences (IAP), } \\
\text { and Tsinghua University (THU) }\end{array}$ & China & $60 \times 128$ \\
\hline GFDL-CM3 & Geophysical Fluid Dynamics Laboratory (GFDL) & USA & $90 \times 144$ \\
\hline GFDL-ESM2G & Geophysical Fluid Dynamics Laboratory (GFDL) & USA & $90 \times 144$ \\
\hline GFDL-ESM2M & Geophysical Fluid Dynamics Laboratory (GFDL) & USA & $90 \times 144$ \\
\hline HadGEM2-CC & Met Office Hadley Centre & UK & $145 \times 192$ \\
\hline INM-CM4 & Institute for Numerical Mathematics & Russia & $120 \times 180$ \\
\hline IPSL-CM5A-LR & Institut Pierre-Simon Laplace & France & $96 \times 96$ \\
\hline IPSL-CM5A-MR & Institut Pierre-Simon Laplace & France & $143 \times 144$ \\
\hline IPSL-CM5B-LR & Institut Pierre-Simon Laplace & France & $96 \times 96$ \\
\hline MIROC5 & $\begin{array}{l}\text { Atmosphere and Ocean Research Institute (The University of Tokyo), } \\
\text { National Institute for Environmental Studies, and } \\
\text { Japan Agency for Marine-Earth Science and Technology }\end{array}$ & Japan & $128 \times 256$ \\
\hline MIROC5-ESM & $\begin{array}{l}\text { Japan Agency for Marine-Earth Science and Technology, } \\
\text { Atmosphere and Ocean Research Institute (The University of Tokyo), } \\
\text { and National Institute for Environmental Studies }\end{array}$ & Japan & $64 \times 128$ \\
\hline MIROC5-ESM-CHEM & $\begin{array}{l}\text { Japan Agency for Marine-Earth Science and Technology, } \\
\text { Atmosphere and Ocean Research Institute (The University of Tokyo), } \\
\text { and National Institute for Environmental Studies }\end{array}$ & Japan & $64 \times 128$ \\
\hline MPI-ESM-LR & Max Planck Institute for Meteorology (MPI-M) & Germany & $96 \times 192$ \\
\hline MPI-ESM-MR & Max Planck Institute for Meteorology (MPI-M) & Germany & $96 \times 192$ \\
\hline MRI-CGCM3 & Meteorological Research Institute & Japan & $160 \times 320$ \\
\hline NorESM1-M & Norwegian Climate Centre & Norway & $96 \times 144$ \\
\hline
\end{tabular}


Table 5 Mean and the associated monthly (first number within brackets) and interannual (second number within brackets) variabilities of each index. Variability is defined by two standard deviations. All values are expressed as a ratio of days.

\begin{tabular}{|cc|c|c|}
\hline & & DS15 & PR99 \\
\hline \multirow{2}{*}{ APHRO } & NCK & $0.22(0.26 / 0.10)$ & $0.01(0.02 / 0.01)$ \\
& SC & $0.08(0.20 / 0.09)$ & $0.03(0.02 / 0.02)$ \\
\hline HG3 & NCK & $0.15(0.16 / 0.12)$ & $0.02(0.02 / 0.02)$ \\
& SC & $0.01(0.04 / 0.03)$ & $0.05(0.02 / 0.02)$ \\
\hline \multirow{2}{*}{ HRC } & NCK & $0.32(0.28 / 0.16)$ & $0.03(0.02 / 0.02)$ \\
& SC & $0.21(0.36 / 0.22)$ & $0.04(0.02 / 0.02)$ \\
\hline
\end{tabular}

Table 6 Correlation coefficients between monsoon index (section 4) anomalies and each extreme index anomalies, computed from monthly data, for the APHRO observations (AP) and models (HG3 and HRC).

\begin{tabular}{|c|c|c|c|c|c|c|c|c|c|c|}
\hline & & \multicolumn{3}{|c|}{ EASJ-JJA } & \multicolumn{3}{|c|}{ WNPSM-JJA } & \multicolumn{3}{|c|}{ EAWM-DJF } \\
\hline & & $\mathrm{AP}$ & HG3 & HRC & $\mathrm{AP}$ & HG3 & HRC & $\mathrm{AP}$ & HG3 & HRC \\
\hline \multirow{2}{*}{ DS15-DJF } & NCK & & & & & & & 0.07 & 0.01 & 0.03 \\
\hline & $\mathrm{SC}$ & & & & & & & 0.14 & 0.23 & 0.12 \\
\hline \multirow{2}{*}{ PR99-JJA } & NCK & 0.05 & 0.12 & -0.10 & -0.11 & -0.02 & -0.30 & & & \\
\hline & $\mathrm{SC}$ & -0.12 & 0.12 & -0.20 & -0.36 & 0.25 & -0.09 & & & \\
\hline
\end{tabular}

Table 7 Same as Table 6 but correlations are computed from seasonal data.

\begin{tabular}{|c|c|c|c|c|c|c|c|c|c|c|}
\hline & & \multicolumn{3}{|c|}{ EASJ-JJA } & \multicolumn{3}{|c|}{ WNPSM-JJA } & \multicolumn{3}{|c|}{ EAWM-DJF } \\
\hline & & AP & HG & HR & $\mathrm{AP}$ & $\mathrm{HG}$ & HR & AP & HG & HR \\
\hline \multirow{2}{*}{ DS15-DJF } & NCK & & & & & & & -0.02 & -0.06 & -0.06 \\
\hline & $\mathrm{SC}$ & & & & & & & 0.10 & 0.17 & -0.02 \\
\hline \multirow{2}{*}{ PR99-JJA } & NCK & 0.08 & 0.12 & 0.10 & -0.20 & 0.05 & -0.37 & & & \\
\hline & $\mathrm{SC}$ & -0.32 & 0.13 & 0.29 & -0.46 & -0.40 & -0.20 & & & \\
\hline
\end{tabular}


Acknowledgements This work was supported by the National Science Council, Taiwan, under Grant NSC-

569 100-2119-M-001-029-MY5, and by the UK-China Research and Innovation Partnership Fund through the

570 Met Office Climate Science for Service Partnership (CSSP) China as part of the Newton Fund. 


\section{References}

D. N. Barnett, S. J. Brown, J. M. Murphy, D. M. H. Sexton, and M. J. Webb. Quantifying uncertainty in changes in extreme event frequency in response to doubled $\mathrm{CO} 2$ using a large ensemble of GCM simulations. Clim. Dynam., 26:489-511, 2006.

B. Barnier, G. Madec, T. Penduff, J.-M. Molines, A.-M. Treguier, J. Le Sommer, A. Beckmann, A. Biastoch, C. Bning, J. Dengg, C. Derval, E. Durand, S. Gulev, E. Remy, C. Talandier, S. Theetten, M. Maltrud, J. McClean, and B. De Cuevas. Impact of partial steps and momentum advection schemes in a global ocean circulation model at eddy permitting resolution. Oc. Dynam., 4, 2006. doi: 10.1007/s10236-006-0082-11.

C.-A. Chen, C. Chou, and C.-T. Chen. Regional perspective on mechanisms for tropical precipitation frequency and intensity under global warming. J. Climate, 25:8487-8501, 2012.

J.-H. Chen and S.-J. Lin. Seasonal prediction of tropical cyclones using a 25-km resolution general circulation model. J. Climate, 26:380-398, 2012.

C. Chou and J. D. Neelin. Mechanism of global warming impacts on regional tropical precipitation. J. Climate, 17:2688-2701, 2004.

C. Chou, J. D. Neelin, C.-A. Chen, and J.-Y. Tu. Evaluationg the "Rich-GetRicher"mechanism in tropical precipitation change under global warming. J. Climate, 22:1982-2005, 2009.

C. Chou, C.-A. Chen, P.-H. Tan, and K.-T. Chen. Mechanisms for global warming impacts on precipitation frequency and intensity. J. Climate, 25:3291-3306, 2012.

J. H. Christensen, B. Hewitson, A. Busuioc, A. Chen, X. Gao, I. Held, R. Jones, R. K. Kolli, W.-T. Kwon, R. Laprise, V. Maga na Rueda, L. Mearns, C. G. Menéndez, J. Räisänen, A. Rinke, A. Sarr, and P. Whetton. Regional Climate Projections. In: Climate Change 
2007: The Physical Science Basis, Contribution of Working Group I to the Fourth Assessment Report of the Intergovernmental Panel on Climate Change [Solomon, S., D. Qin, M. Manning, Z. Chen, M. Marquis, K.B. Averyt, M. Tignor and H.L. Miller (eds.)]. Cambridge University Press, Cambridge, United Kingdom and New York, NY, USA, 2007.

Y. Ding. Monsoon over China. Kluwer Academic Publisher, 1994.

Y. Ding. The variability of the Asian Summer Monsoon. J. Meteor. Soc. Japan, 85B:21-54, 2007.

A. Duan, J. Hu, and Z. Xiao. The tibetan plateau summer monsoon in the CMIP5 simulations. J. Climate, 26:7747-7766, 2013.

N. Freychet, H.-H. Hsu, C. Chou, and C.-H. Wu. Asian summer monsoon in CMIP5 projections: A link between the change in extreme precipitation and monsoon dynamics. $J$. Climate, 28:1477-1493, 2015.

F. Giorgi, E.-S. Im, E. Coppola, N. S. Diffenbaugh, X. J. Gao, L. Mariotti, and Y. Shi. Higher hydroclimatic intensity with global warming. J. Climate, 24:5309-5324, 2011.

P.-C. Hsu, T. Li, H. Murakami, and A. Kitoh. Future change of the global monsoon revealed from 19 cmip5 models. J. Geophys. Res. Atmos., 118:1247-1260, 2013. doi: 10.1002/jgrd.50145.

G.J. Huffman, R. F. Adler, D.T. Bolvin, G. Gu, E.J. Nelkin, K.P. Bowman, Y. Hong, E.F. Stocker, and D.B. Wolff. The TRMM multi-satellite precipitation analysis: Quasi-global, multi-year, combined-sensor precipitation estimates at fine scale. J. Hydrometeor, 8:38$55,2007$.

T. Inoue and H. Ueda. Delay of the first transition of Asian summer monsoon under global warming condition. SOLA, 7:081-084, 2011.

J.-G. Jhun and E.-J. Lee. A new East Asian winter monsoon index and associated characteristics of the winter monsoon. J. Climate, 17:711-726, 2003. 
C. Jones and L. M. V. Carvalho. Climate change in the South American monsoon system: Present climate and CMIP5 projections. J. Climate, 26:6660-6678, 2013.

E. Kalnay, M. Kanamitsu, R. Kistler, W. Collins, D. Deaven, L. Gandin, M. Iredell, S. Saha, G. White, J. Woollen, et al. The NCEP/NCAR 40-year reanalysis project. Bull. Amer. Meteor. Soc., 77:437-470, 1996.

Y. Kamae, M. Watanabe, M. Kimoto, and H. Shiogama. Summertime land-sea thermal contrast and atmospheric circulation over East Asia in a warming climate-Part I: Past changes and future projections. Clim. Dynam., 43:2553-2568, 2014.

V. V. Kharin and F. W. Zwiers. Estimating extremes in transient climate change simulations. J. Climate, 18:1156-1173, 2005.

A. M. G. Klein Tank, F. W. Zwiers, and X. Zhang. Guidelines on analysys of extremes in a changing climate in support of informed decisions for adaption. World Meterological Organization, 56:1156-1173, 2009.

S. Kusunoki and O. Arakawa. Change in the precipitation intensity of the East Asian summer monsoon projected by CMIP3 models. Clim. Dynam., 38:2055-2072, 2012. doi: 10.1007/s00382-011-1234-7.

L. Li and Y. Zhang. Effects of different configurations of the East Asian subtropical and polar front jets on precipitation during the Mei-Yu season. J. Climate, 27:66606672, 2008.

S.-J. Lin. A vertically lagrangian finite-volume dynamical core for global models. Mon. Wea. Rev., 132:2293-2307, 2004.

G. Liu, P. Zhao, and J. Chen. Preceding factors of summer Asia-Pacific oscillation and the physical mechanism for their potential influences. J. Climate, 28:2531-2543, 2015.

S. Matsumura, S. Sugimoto, and T. Sato. Recent intensification of the Western Pacific subtropical high associated with the East Asian summer monsoon. J. Climate, 28:2873- 
2883, 2015.

G. A. Meehl, J. M. Arblaster, and C. Tebaldi. Understanding future patterns of increased precipitation intensity in climate model simulations. Geophys. Res. Lett., 32:L18719, 2005. doi: 10.1029/2005GL023680.

G. A. Meehl, T. F. Stocker, W. D. Collins, P. Friedlingstein, A. T. Gaye, J. M. Gregory, A. Kitoh, R. Knutti, J. M. Murphy, A. Noda, S. C. B. Raper, I. G. Watterson, A. J. Weaver, and Z.-C. Zhao. Global Climate Projections. In: Climate Change 2007: The Physical Science Basis. Contribution of Working Group I to the Fourth Assessment Report of the Intergovernmental Panel on Climate Change [Solomon, S., D. Qin, M. Manning, Z. Chen, M. Marquis, K.B. Averyt, M. Tignor and H.L. Miller (eds.)]. Cambridge University Press, Cambridge, United Kingdom and New York, NY, USA, 2007.

S.-K. Min, S. Legutke, A. Hense, U. Cubasch, W.-T Kwon, J.-H. Oh, and U. Schlese. Projected changes in Asian summer monsoon in RCP scenarios of CMIP5. Atmos. and Oc. Sci. Lett., 5:43-48, 2012.

W. M. Putman and S.-J. Lin. Finite-volume transport on various cubed-sphere grids. $J$. Comput. Phys., 227:55-78, 2007.

C. S. Ramage. Monsoon Meteorology, volume 15 of Int. Geophy. Ser. Academic Press, San Diego, California, 1971.

N. A. Rayner, D. E. Parker, E. B. Horton, C. K. Folland, L. V. Alexander, and D. P. Rowell. Global analyses of sea surface temperature, sea ice, and night marine air temperature since the late nineteenth century. J. Geophys. Res., 108:4407, 2003. doi: 10.1029/2002JD002670.

J. Risnen. CO2-induced impact of increasing $\mathrm{CO} 2$ on monthly-to-annual precipitation extremes: analysis of the CMIP2 experiments. Clim. Dynam., 24:309-323, 2005. 
E. Scoccimarro, S. Gualdi, A. Bellucci, M. Zampiery, and A. Navara. Heavy precipitation events in a warmer climate: Results from CMIP5 models. J. Climate, 26:7902-7911, 2013.

R. Seager, N. Naik, and G. A. Vecchi. Thermodynamic and dynamic mechanisms for largescale changes in the hydrological cycle in response to global warming. J. Climate, 23: 46514668, 2010.

A. Seth, S. A. Rauscher, M. Biasutti, A. Giannini, S. J. Camargo, and M. Rojas. CMIP5 projected changes in the annual cycle of precipitation in monsoon regions. J. Climate, 26:7328-7351, 2013.

C.-J. Shiu, S. C. Liu, C. Fu, A. Dai, and Y. Sun. How much do precipitation extremes change in a warming climate? Geophys. Res. Lett., 39, 2012.

S. Sorooshian, K. L. Hsu, X. Gao, H. V. Gupta, B. Imam, and D. Braithwaite. Evaluation of PERSIANN System SatelliteBased Estimates of Tropical Rainfall. Bull. Amer. Meteor. Soc., 81:2035-2046, 2000.

G. L. Stephens and T. D. Ellis. Controls of global-mean precipitation increases in global warming GCM experiments. J. Climate, 21:6141-6155, 2008.

K. E. Taylor. Summarizing multiple aspect of model performance in a single diagram. $J$. Geophys. Res., 106:7183-7192, 2001.

C. Tebaldi, K. Hayhoe, M. Arblaster, and G. A. Meehl. Going to extremes. Climatic Change, $79,2006$.

K. E. Trenberth, A. Dai, R. Rasmussen, and D. Parsons. The changing character of precipitation. Bull. Amer. Meteor. Soc., 84:1205-1217, 2003.

A. G. Turner and H. Annamalai. Climate change and the South Asian summer monsoon. Nature Clim. Chang., 2:587-595, 2012. doi: 10.1038/NCLIMATE1495.

B. Wang. The Asian Monsoon. Praxis Publishing Ldt, Chichester, UK, 2006. 
B. Wang and Q. Ding. Changes in global monsoon precipitation over the past 56 years. Geophys. Res. Lett., 33:L06711, 2006. doi: 10.1029/2005GL025347.

B. Wang, Z. Wu, J. Li, J. Liu, C.-P. Chang, Y. Ding, and G. Wu. How to measure the strength of the East Asian summer monsoon. J. Climate, 21:4449-4463, 2008.

L. Wang and W. Chen. An intensity index for the East Asian winter monsoon. J. Climate, 27:2361-2374, 2014.

K. D. Williams, C. M. Harris, A. Bodas-Salcedo, J. Camp, R. E. Comer, D. Copsey, D. Fereday, T. Graham, R. Hill, T. Hinton, P. Hyder, S. Ineson, G. Masato, S. F. Milton, M. J. Roberts, D. P. Rowell, C. Sanchez, A. Shelly, B. Sinha, D. N. Walters, A. West, T. Woollings, and P. K. Xavier. The met office global coupled model 2.0 (GC2) configuration. Geosci. Model Dev., 88:1509-1524, 2015. doi: 10.5194/gmd-88-1509-2015.

A. Yatagai, O. Arakawa, K. Kamiguchi, H. Kawamoto, M. I. Nodzu, , and A. Hamada. A 44-year daily gridded precipitation dataset for Asia based on a dense network of rain gauges. SOLA, 5:137-140, 2009. doi: 10.2151/sola.2009-035.

A. Yatagai, K. Kamiguchi, O. Arakawa, A. Hamada, N. Yasutomi, and A. Kitoh. APHRODITE: Constructing a long-termdaily gridded precipitation dataset for Asia based on a densenetwork of rain gauges. Bull. Amer. Meteor. Soc., 93:1401-1415, 2012. 